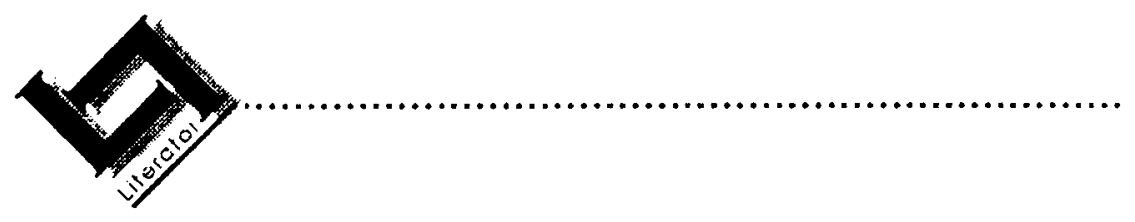

\title{
Woord en wonder
}

'n Ooppraat ...

\section{engemi ferreira}

Und so lang du das nicht hast

Dieses Stirb und Werden, bist du nur ein trüber Gast

Auf der dunkle Erde - Goethe.

\section{Saamloop op 'n ontdekkingstog}

Hierdie artikel heet "Woord en wonder", ter herinnering aan my en baie van ons se studentedae toe óns koppe oopgepraat en/of -geskryf is deur 'n reeds byna vergete geslag litratore, van wie A.P. Grové met sy gelyknamige klein bundel essays rondom die poësie een van die invloedrykstes was.

My artikel handel oor die heel belangrikste ding in die lewe van 'n skrywer; iets waarsonder nie een van ons kan klaarkom nie - maar daarvoor moet ek 'n wyle teruggaan. Om die waarheid te sê, 'n hele wyle. Ek wil u gids wees op 'n ontdekkingsreis wat ek self al 'n paar keer geloop het en sekerlık weer en weer sal loop tot die einde. So wil ek dan sê: "In die begin was die Woord, en die Woord wás God en die Woord was mét God ..." want dit gaan veral oor woorde.

Die woorde wat aan die begin was, en is en sal wees; die woord waarmee God die aarde geskape het binne die kosmos. Die skepping; dus: 'n genesis; ' $n$ verhaal wat so begin:

In die begin het God die hemel en die aarde geskep. Die aarde was woes en leeg en heeltemal onbewoonbaar. Dit was donker in die diep waters, maar die Gees van God het oor die waters gesweef. En toe het God gesê: 'Laat daar Lig wees!' En daar was lig. 
God het gesien die lig was goed, en hy het die lig en die donker van mekaar geskei. God het die lig toe 'dag' genoem en die donker het

Hy 'nag' genoem. Dit was aand en dit was môre, die eerste dag.

Dit was ook die heel eerste verhaal met ' $n$ einde wat bietjie verder vorentoe loop, want na ses dae arriveer daar toe die eerste mense op die toneel, met húlle verhaal van ont-dekking.

Die verhaal, soos $u$ alte goed weet, gaan min of meer oor 'n ou wat alleen gewoon het in ' $n$ tuin en later baie verveeld geraak het. Toe gaan hy na die Eienaar van die tuin en vra hom: "Asseblief Here, kan u nie maar vir my iets gee om mee te speel nie, ek is so verveeld".

En toe sê die Eienaar van die tuin: "Ek kan ja, maar dit sal jou 'n arm én 'n been kos".

Adam, want dit was die man se naam, stap eenkant toe, bedruk oor hy nóg arm, nóg been wil verloor, en dink. Toe vra hy die tuin se Eienaar, opgewonde oor hy 'n blink plan uitgedink het: "Here, sê my, wat sal U my gee vir 'n ribbebeen?" En soos u weet, kry Adam sy rib-substituut en sy word toe sy gemeneregvrou, Eva. Omdat albei vegetariërs was, kon hulle in die tuin met baie vrugte en groente aanbly, mits hulle alles sou bewerk. Slegs van een besonderse boom het die Eienaar van die tuin hulle die gebruik ontsê en hulle gewaarsku dat hulle sekerlik sou sterf indien hulle sou eet van dié boom se vrugte

Elke dag teen die aand het die Tuinier in die tuin gaan wandel, met Adam en Eva gesels, en na die boom met die vrugte van sy kennis omgesien. Maar een spesifieke aand - die aand na Eva en Adam van die vrugte geëet het - moes Hy hard roep: "Adam! Waar is jy?" want uit skaamte oor hy kaal was, het Adam weggekruip, en net daar, in 'n oogwink, het hy die heel eerste idioom geskep. Soos met die meeste idiome en ander sinsnedes het daar 'n mate van dekonstruksie plaasgevind waarin die "toe" na 'n paar eeue verval het. Wat oorgebly het, was natuurlik: die vere maak die voël.

Ewentwel. Die storie van die skepping, en die boom in die middel van die tuin, en Adam en Eva vir wie God velklere moes aantrek en wie die opdrag gehad het om name te gee aan al die "dinge", en wie God uit die tuin moes verjaag, is inderdaad die storie van elke skrywer wat van nuut af 'n boek maak. In Fugitive Pieces, geskryf deur Anne Michaels, gebruik die hoofkarakter hierdie Joodse gesegde: "With a book in your hand you are a pilgrim at the gates of a new city". Dit beteken, alles is nuut, 'n begin. En ja, dit word 'n reis. 'n Ontdekkingsreis. Soos toe Bartolomias Dias nuwe wêrelde ingevaar het, in sy skip na Afrika gereis het, en 'n paar kruise kuslangs geplant het. En toe hy die lieflike baai van 
Kaapstad teëkom, het hy dit Cabo de Boa Esperanza genoem, want dit was vir hom wonderlik om te sien wat hy glo niemand nog ooit van tevore gesien het nie. En daar sit Dias in sy boot en hy haal sy dagboek uit en sy pen, en hy begin die hele genesis van sy ontdekkings opteken vir die nageslag, want dit wat vir mens mooi is, wil jy met ander deel en so word hy van die eerstes om "woorde" neer te skryf oor Afrika strokiesprente was toe lank reeds opgeteken teen die wande van grotte in al die bergreekse van dié donker kontinent, en waar daar nie grotte was nie, sommer op klippe in die veld.

Maar Dias dag hy is die eerste om hierdie wêreld te ontdek, want alles was nog woes en leeg soos aan die begin. En so word hy deel van die helde van 'n vervloë tyd. Dié eerste ontdekkingsreisigers het inderdaad virgin land betree, om nou nie dieper in die saak in te dring nie. Maar hulle het ook, deur middel van waarnemings, dié maagdelike wêreld opgeteken, as't ware ontbloot vir die tuisblyers; die misterie daarvan oopgeskryf, en ont-dek, deur kennis daaroor aan lesers deur te gee.

\section{Die oopskryf van 'n misterie}

Die leser van 'n nuwe storie of 'n nuwe boek sal ook so - al lesende virgin worlds betree, en dalk nog virgin words indien die woorde so raak en goed gekies is dat hulle vir hom of haar nuut word. Dit val saam met iets aan die ander kant van die spektrum, wat ewe belangrik is: die begin - toe die woord was; selfs nog voor die woord daar was. En hier praat ek van die woord in ons, die onhoorbare woord of idee, die gedagte; die ontstaan van dinge. Dit wat God gedink het voor Hy die universum met son en maan en sterre en al die planete en spesifiek ons aarde geskape het. Hoe sou God dink in daardie oomblik toe alles nog chaos was? Seker tog maar soos wat 'n God sou dink wanneer Hy begin skep! So ... ordenend? So bevestigend van alles wat groots is en die landskap; so vormend, dat ons, die wesens wat $\mathrm{Hy}$ daarin geplaas het, dit kan waardeer en eer. Wat boos is, het ons as mense self hier ingeteken en ingeskryf. En sal ons self die manier moet vind om die bose te óntsê sodat ons weer kan weet hóé God gedink het in die begin.

Maar weet $u$, ons as skeppers en ont-dekkers, dink ook so bevestigend in daardie moment van chaos voor óns begin om (orde) te skep en 'n storie te vertel of 'n boek te skryf. En ons het eweneens iemand aan die ander kant nodig om te waardeer wat ons doen. Want ons vertel die stories wat nie vergeet mag word nie. Dis ons wat die aarde vol bloed en beendere oopskryf en verduidelik en lewend hou, sodat almal anders wat nie skryf nie kan lees, want ons maak die kompos vir die voortbestaan van lewe. Ons bevestig die toekoms. 
As $u$ uself dan sien as ' $n$ leser wat só móét lees, wat is dit wat u graag wil lees? Natuurlik, bedryfsekonomiese literatuur as dit u nering is. Of geskiedenis, of die herkoms van kristalle, of oor die struktuur van plante. Of dalk die wonderlike boek oor alles wat is, genaamd Sensitive Chaos deur Theodor Schwenk waarin hy onder andere volgens Benninghoff se spesiale metodes wys hoe water se vloeivorms herhaal word in byvoorbeeld die menslike femur of skouerblaaie en ander sulke vergelykende mirakels wat aandui hoe alle dinge oral inmekaar teruggevind kan word.

Dit is só, en dit is wonderlik. Maar indien u nering stories is, dan wil u self ook stories lees. En hoe moet die stories lyk? Vir my moet die woorde ingekleur wees met wonder. Ek moet veral wonder terwyl ek lees oor hoe dit vir iemand moontlik was om dié tema raak te dink, soos Perfume van Süsskind wat handel oor 'n karakter - seun van die vishandelaar wat glad geen vel- of persoonsreuk besit nie en dan land in 'n parfuumfabriek waar hy die geure van nuwe parfume moet uitken en beskryf. Of om 'n roman vanuit so 'n unieke invalshoek te benader, soos die een en twintigjarige Richard Mason wat sy debuutroman skryf vanuit die insig van 'n sewentig-jaar-oue man wat pas sy vrou vermoor het in The Drowning People, en deur wie se vertelling die biografie van 'n paar mense gestalte kry om nog lank na die lees van die boek deel te wees van jou bestaan. Of om die teerheid van liefde te jukstaponeer teenoor die wreedheid van oorlog sonder om een van die twee banaal te maak, soos Louis de Berniêres in Captain Corelli's Mandolin. Of om alleen langs die dam te sit met jou deernis vir Vossie, die hoofkarakter in George Weideman se Draaijakkals - oor sy taal en sy vernuf; en sy droefnis; of om jou stom en week te huil by die lees van Disgrace, waarmee John Coetzee ons vereer het deur weer eens die Booker-prys te verower.

So wil ek wonder. Maar meer nog. Ek wil vervul wees met die wonder van die woord, soos in die byna driehonderd-bladsy-lange roman vol liriese prosa genaamd Fugitive Pieces, waarvan 'n resensent gesê het: "Read this and you wil never take life for granted again". Inderdaad. Dié boek wil my ook verhoed om ooit weer woorde as vanselfsprekend te aanvaar.

Anne Michaels het klaarblyklik sestien jaar lank geskryf aan haar twee maal pryswennerroman Fugitive Pieces. Hierin het sy stelselmatig met haar beiteltjie die taal van haar verhaal verfyn tot dit gegloei het soos robyn: terselfdertyd gevul met lig en bloed; met die wonder van lewe en die ontsag vir dood. 
Woord en Wonder. Dis amper soos die groot poorte van Lewe: Geboorte en Dood, want sonder taal is ons niks en sal ons niks weet nie. En sonder die magiese sal ons verval in alledaagse verveling - en niks wil weet nie. En tog. Toe God die aarde geskape het, met die tuin van Eden waarin hy Adam en Eva laat woon het, het hy hulle gesê om nie van die Boom van Kennis te eet nie, want dan sou hulle sekerlik sterf. Hoekom is dit so 'n sonde om te weet? Wat maak die besit van kennis strafbaar met die dood?

Dis iets wat my deur baie nagte besig hou en die slotsom waartoe ek gekom het, is enersyds dat die verlies van onskuld so erg is, dat die mens wat dit verloor het, nie wil leef nie. Andersyds, dat om te vroeg te weet, erger is as om nie te wil leef nie.

Ek weet nie wie van $u$ iets weet van Kaspar Hauser nie. Hy was volgens oorlewering - die Prins van Baden, buite-egtelike kind van Carl von Baden en Josephine de Beauharnais. Kaspar Hauser is aangehou in 'n sel waarin niks anders was as ' $n$ bed en 'n hobbelperd nie. Oor die perd het Susan Vega ' $n$ liedjie geskryf wat $u$ dalk al gehoor het. Hauser het nooit enige mense gesien nie, sy kos is deur ' $n$ opening in die deur geskuif terwyl hy nog geslaap het. Op 'n dag het hy opgedaag op die stadsplein van Nuremberg en kon aanvanklik glad nie kommunikeer met mense nie. By hom het hy twee briewe gehad oor sy herkoms, maar wat later as vals bestempel is. Die mense wat hom gevind het, het eers van hom 'n uitstalpop gemaak, en toe gedwing om een van hulle te word; 'n mens soos hulle. Hulle het hom leer vleis eet en leer drink. Hulle wou hom leer lieg oor sy herkoms. Hulle het al sy natuurlike vermoëns van hom weggeneem, soos om oor 'n afstand van myle 'n peerboom in bloei te ruik. En na 'n paar jaar het hulle hom vermoor. Die puer aeternus, die ewige kind wat so intens en so vinnig met die ontredderde wêreld in aanraking sou kom, moes sterf by die verlies van sy onskuld.

\section{Skryf hou die wonder van die woord lewend}

Wanneer ons skryf en ons ontneem ons verháál sy onskuld, sterf die verhaal - nog voor dit gelees kan word. Dit beteken tog dat ons so moet skryf dat ons die wonder van die woord lewend hou. Nie net die kreatiewe woord nie, maar ook die taal wat ons praat in ons stories, die taal wat ons moeders ons geleer het en van wie Pesoa gesê het: "My taal is my vaderland". En so sal dié taal bly leef in al sy beeldende rykdom van Flaaitaal, Tsotsitaal, Kaaps, Griekwa, Trônsvôls, Namakwalands, haai ja, en die hoë gang van akademie se borste teen die wind, en goddank, ook die gestrooptheid van die gewone Afrikaanse skelet wat oral oor die aarde uit kaste klim. 
Waarom en hoe skryf ek? Ek skryf vinnig, maar hersien stadig, omdat ek baie mense het wat aanspraak maak op my tyd en aandag. Ek sien dit nie as ' $n$ verlies nie, al frustreer dit my ongekend, want so kry ek kans om my beiteltjie te gebruik. Ek het 'n roman afgehandel wat sowat ses jaar gelede sy ontstaan gehad het in woede. Woede oor die politieke en emosionele toestande waarin ons in die land verkeer het en miskien gaandeweg al meer verkeer en waaroor seker kort voor lank uitbarstings op meer as een gebied sal kom. My uitbarsting is gegiet in 'n storie geskryf deur ' $n$ wit vrou, boonop kunstenaar, in Afrika en dit gee die angs weer waarmee so iemand opgeskeep sit.

Miskien sal die storie nie werk vir 'n wit man of 'n swart man nie, maar indien u uself die kans sou gee om die verhaal te lees, sou u verstaan hoe ek en baie van my susters voel op die huidige oomblik. Hulle hoef nie eens almal wit te wees nie, maar ek dink dalk moet hulle maar Afrikaans praat. Op sigself het dit geen waarde nie, behalwe om aan te dui hoe eners ons almal is. Die wiel van angs wat baie swart mense in die verlede gevoel het, het nou gedraai, en dit is ons beurt. Ons is bang ons taal gaan verdwyn. Ons is bang ons gaan aangerand word. Ons is bang ons kinders gaan nie werk kry nie. Ons is bang die hele regering gaan ook oppak en verdwyn en daar gaan niks oorbly van alles wat "ons" hier tot stand gebring het nie en ons is bang die hele beskawing gaan verdwyn en stort oor die rand van Afrika se glas.

In dié roman wat voorlopig nog heet Anderkant die eiland, het ek probeer om die gegewe wat my so woedend gemaak het, te sif tot die essensie. $\mathrm{Na}$ ek dit heelwat herkou het, het ek verstaan dat die meeste van my woede gerig is teen die dinge wat deur middel van die pers, die media, die radio, die teevee, die advertensieborde langs die strate, die toesprake na my ore kom sonder dat ek dit kan keer. Ek het begin besef ek ly aan woordbesoedeling. Ons is deesdae waar ons nie meer die bome in die bos kan raaksien nie. Daar is soveel woorde dat ons nie meer die verhale kan hoor wat veronderstel is om ons vry te maak in hierdie land nie.

Ek het die roman se woorde begin opdeel in faksies om te kyk hoe dit verskil van die woorde in my eie wêreld. En ek wil nie graag die verrassingselement uit 'n moontlike lees van die roman verwyder nie, maar ek glo dis dalk iets nuwerigs. Daar is iets van elke soortwoord gebruik om die geheel te maak wat roman heet. En ek weet nou nie meer wat betéken roman nie, maar dit sluit vir my aan by my eie lewensfilosofie wat ek put uit die romantiek. Daardie tyd toe ridders en prinse nog ridders en prinse was, en hulle dit moontlik gemaak het vir vroue en prinsesse om soos vroue en prinsesse op te tree. Die roman het my deur te ont-dek, laat uitkom by die ontdekking van hoe eners my 
eie angst as skrywer is met die angst van alle skrywers. Hoe bang ons almal is om te ontbloot, te wys. En ek hoop wat oorgebly het, is 'n paar karakters wat vereenselwig kan word met die universele.

Tussen hakies, na uitgewers en keurders die roman beetgehad het, het hulle daarin geslaag om my al die woede en frustrasie te laat uithaal, en wat toe oorgebly het, het vir my gevoel soos 'n papperige teksie oor 'n veranderende lewensituasie, waarin baie van ons besig is om onder te gaan, hetsy deur waansin of selfmoord of sommer net deur te verdwyn onder die mat by die voordeur.

\section{As ons stories daar is, bestaan ons!}

En as ons dan oor die rand van Afrika se glas moet stort - wat daarvan? As ons stories daar is, is ons daar; bestaan ons. As ons die vermoë gehad het om in elke storie, hoe klein of hoe gering, die waarheid kaalkop aan te spreek, hoe kan dit dan anders as om te bly voortleef soos wat die Grieke se mites nog steeds veel helderder leef as dié van die Romeine, wat al reeds te veel van hulle onskuld verloor het. En as ons so skryf dat ons al skrywend self ook tot begrip kom, hoe kan ons dan anders as om by mekaar uit te kom?

Een van die redes vir ons ondergang, glo ek, is 'n onrusbarende verskynsel onder die mense wat vir die siel behoort te sorg, predikante en teoloë, wat ' $n$ veldtog op tou het om die bestaan van die siel te ontken. Van die gees wil ek nie eens praat nie, en hierdie is 'n totaal ander onderwerp, maar elke mens wat al ooit gehuil of gelag het, behoort te weet hoe die siel verdonker of verhelder wanneer die emosionele lewe daaroor gly. Want dis inderdaad daardie deel van ons wat wakker word snags wanneer ons slaap, en die dag se gebeure aanskou of beleef om uit te vind wat sy as voedsel kan inneem en wat sy moet verwerp. Die gedeeltes wat as voedsel aangewend word, is die wat aan ons die skeppende kragte verleen en hulle word opgebruik en ingeneem deur die kosmos om dan weer terug te keer as 'n soort reën. Die verworpe gedeeltes daarenteen, verlaat ons nooit heeltemal nie: ons bly dit saamsleep as 'n soort skrootwerf van ongebruikte onderdele saamgeflans uit die dag se indrukke. Dit is wat ons siek maak.

Ons moet weer oor begin. Ons moet kyk na waarmee ons werk en besluit of dit nodig is dat ons daaraan onderworpe hoef te wees: teeveeaanbieders wat vir ons dink, radioaanbieders wat vir ons besluit, notas, briewe, berigte, verslae, vraestelle, meningpeilings, advertensies, koerante, boeke, gemorspos, gemorsboeke en tydskrifte, en ek bedoel nie Lyfspel of Playboy nie, want dit dien nog 'n sekere doel. Ek praat veral van die "Chickensoup for the soul"-boeke en tydskrifte, waarin die siel 
gesien word as 'n brose ou vlindertjie wat in watte verpak moet wees dat sy tog nie seerkry nie. Min weet hülle wat dié soort dinge skryf, dit is juis watte wat die siel pynig. Ons sal nooit die besoedeling van die siel kan genees met sop en watte nie. Ons moet liefs teruggaan na waar die siel was toe sy nog gevoed was deur feëverhale en legendes, want selfs ons hedendaagse verhale is maar net 'n weerspieëling van vervloë mites. Ons moet teruggaan na die begin, na eenvoud, en onskuld, en dit in ons stories behou en dan sal die stories hulle self vertel.

\section{Soms nodig om te ont-klee sodat die leser kan ont-dek}

Ek het gesê ek sal terugkom na die dag toe God Adam en Eva uit die tuin gejaag het, toe hy vir hulle velklere moes maak om hulle skaamte te bedek. Hoe sou ons as skrywers voel sonder die wegkruipplekke van ons velklere? Sou ons die skaamte kon oorleef deur naak voor die leser te staan? Dis waarna die leser soek in hierdie tyd van postmodernisme en dekonstruksie. Die publiek (aan wie die kunstenaar per slot van sake behoort) wil alles weet van hom, elke moesie, elke puisie. Hy roep ons: waar is jy en ons bly wegkruip agter nikssegende gemeenplasighede wat hom nie kan voed nie. Persoonlik dink ek dis soms nodig om te ont-klee sodat die leser kan ontdek. Maar ek dink 'n mens moet dit op so 'n manier doen dat wat die leser vind, nie die skrywer se naakte siel is nie, maar sy of haar eie. Mens kan amper sê dat die leser hom of haar moet kan spieël in die skrywer se beeltnis van hom- of haarself, want om so die self te ont-dek, is alles deel van onskuld en wonder, al klink dit ook hoe paradoksaal.

\section{Ontgin die taal se moontlikhede}

'n Laaste woord: Elkeen van ons het ' $n$ heel besonderse verhaal. $U$ eie verhaal. U biografie. Dit sal seker nie regverdig wees as almal gelyktydig die biografieë gaan loslaat net soos wat hulle is nie. Per slot van rekening loop die boekwinkels oor dáárvan. Maar as u die moeite sou doen om u woord te week in wonder, te poets met denke, te sleep deur die hart - wat altyd maar die barometer bly van waarheid of leuen, dán, dan is ek oortuig u verhaal sal anderkant uitkom - geklee in wonderwoorde wat die lesers se harte raak. Dis hoe mens die magiese kragte in die taal ontsluit: wonder daaroor, lag daarmee saam, geniet ons taal se plooibare, singbare, beeldbare eenvoud en sy onuitputlike bron van humor en rumoer. En skryf u stories met 'n pouveer in die hoed, sodat almal kan weet, ons was hier: in Woord, en in Wonder; boonop in Afrikaans. 


\section{Bibliografie}

Coetzee, J.M. 1999. Disgrace. Kaapstad : Vintage.

De Bernières, Louis. 1994. Captain Corelli's Mandolin. London : Minerva Paperbacks

Michaels, Anne, 1997. Fugitive Pieces. London : Bloomsbury Paperbacks

Schwenk, Theodor. 1965. Sensitive Chaos. The Creation of Flowing Forms in Water and Air. In Engels vertaal deur Olive Wicher en Johanna Wrigley met illustrasies deur Walther Roggenkamp. London : Rudolf Steiner Press.

Süsskind, Patrick. 1991. Perfume. London : Penguin Books.

Weideman, George. 1999. Draaijakkals. Kaapstad : Tafelberg.

Kernbegrippe:

bestáán deurdat verhale vertel word

kreatiewe krag van die woord

ontdek

Key concepts:

discover

creative force of the word

existence by means of stories 
